\title{
Assessment of care provision for hypertension at the emergency Department of an Urban Hospital in Mozambique
}

Neusa BAY ${ }^{1}$, Edna JUGA², Carlos MACUACUA ${ }^{3}$, José JOÃO ${ }^{3}$, Maria COSTA ${ }^{3}$, Simon STEWART 4,5 and Ana $\mathrm{MOCUMBI}^{2,5^{*}}$ (D)

\begin{abstract}
Background: Management of hypertension in Mozambique is poor, and rates of control are amongst the lowest in the world. Health system related factors contribute at least partially to this situation, particularly in settings where there is scarcity of resources to address the double burden of infectious and non-communicable diseases. This study aimed to assess the management of hypertension in an emergency department (ED).

Methods: During a pragmatic and prospective 30-day snapshot study (with $24 \mathrm{~h}$ surveillance) and random profiling of one-in-five presentations to the ED of Hospital Geral de Mavalane, Maputo, we assessed patient's flow and care, as well as health facility's infrastructure and resources through direct observation. Reports from pharmacy and laboratory stocks were used to assess availability of diagnostics and medicines needed for hypertension management.

Results: The 1911 hypertensive patients included in the study had several stops during their journey inside the health facility and followed a non-standardized care flow. No clinical protocols or algorithms for risk stratification of hypertension were available. Stock-outs of basic diagnostic tools for risk stratification and medicines were registered. The availability of medicines was $28 \%$ on average.

Conclusions: Critical gaps in health facility readiness to address arterial hypertension seen in ED were uncovered, including lack of clinical protocols, insufficient availability of diagnostics and essential medicines, as well as low affordability of the families to guaranty continuum of care. Innovative financing mechanisms are needed to support the health system to address hypertension.
\end{abstract}

Keywords: Systemic hypertension, Management Cascade, Medicine availability, Affordability

\section{Background}

Hypertension is the leading risk factor for premature death and disability and constitutes an important cause of health services demand worldwide [1]. Global disparities in its prevalence and awareness have been increasing $[2,3]$.

In Mozambique, hypertension prevalence is among the highest in developing countries, and has increased in people aged 25-64 from 33.1 in 2005 to $38.9 \%$ in 2015

\footnotetext{
* Correspondence: amocumbi@gmail.com

${ }^{2}$ Instituto Nacional de Saúde, Vila de Marracuene, Estrada Nacional №1, Parcela N³943, Província de Maputo, Mozambique

${ }^{5}$ Universidade Eduardo Mondlane, Cidade de Maputo, Mozambique

Full list of author information is available at the end of the article
}

(p 0.048) with low awareness (14.5\%), treatment among those aware $(50.1 \%)$ and control among the treated $(44.5 \%)[1,4]$. Hypertension is an important driver of heart failure and stroke in this country $[5,6]$ and thus constitutes a priority in Mozambique's strategic plan for non-communicable diseases (NCD) prevention and control [7]. However, the national health information system still does not systematically perform surveillance of hypertension and its complications.

Initial surveillance data on NCD targeted by the World Health Organization (WHO) global strategy for the prevention and control of NCD showed prominence of hypertension as a cause of poor outcomes [8]. Due to

(c) The Author(s). 2019 Open Access This article is distributed under the terms of the Creative Commons Attribution 4.0 International License (http://creativecommons.org/licenses/by/4.0/), which permits unrestricted use, distribution, and 
the continuing need for major efforts to control infectious endemic diseases in Mozambique, the burden imposed by NCD constitutes a high risk for the sustainability of the health system. Moreover, because no funding mechanisms are available to sustain national NCD program's activities within the National Health Service (NHS) in Mozambique, insufficient investments have been made on health facilities to address this double burden of disease. Our study aimed at describing care provision for hypertensive patients assisted at the emergency department (ED) of a firstreferral urban hospital, often an entry point for patients into the NHS.

\section{Methods}

The National Health System in Mozambique comprises the public sector, the for-profit private sector, the nonprofit private sector and the community sector. The public sector, which is the National Health Service (NHS), is the main provider of health services on a national scale, and is organized into four levels of care (primary - health centres; secondary - district hospitals and general urban hospitals; tertiary - provincial hospitals; quaternary - specialized and sub-specialty hospitals). Treatment and diagnostic resources for the NHS depends on a supply chain structured in 5 levels. The Central Level with three regional warehouses for Southern, Central and Northern Region supplying central and general hospitals and provincial deposits; the Provincial Level with provincial deposits supplying tertiary and lower level facilities, including some rural hospitals and district health centers; the District Level deposits supplying all health facilities in one district. Pharmacies in health centers and community Health Workers - supplied by the nearest district deposits or health centers constitute the primary and community levels, respectively [9]. Levels of prescription have been defined to ensure that each health professional prescribes according to their training background and the health facility level [10]. Care cost is $\$ 0.02$ (1MZN) per appointment, nil for complementary exams and $\$ 0.08$ (5MZN) for each prescription with one or more medicines. The total amount charged corresponds to $0.14 \%$ of the patient's salary, considering the official minimum wage [11].

\section{Setting}

We performed an assessment of hypertension care in patients assisted around the clock at $a$ first-referral hospital in Mozambique's capital city - Hospital Geral de Mavalane (HGM). This is an urban secondary level 265-bed hospital serving a population of nearly 800 , 000; it is a pilot sentinel site for NCD without patient electronic management system, and where hospital identification cards and medical files are used for patients with chronic condition.

\section{Sampling}

During the pilot-phase of the MOZambique snApshot of emeRging Trends (MOZART) Disease Surveillance Study cohort [12], with a target of at least 1000 patients per health facility studied, and based on previous knowledge of the caseload of patients in the hospital a ratio of selected presentations of 5 to 1 was established to achieve this minimum target. Over 30 consecutive days with 24-h coverage patients of any age presenting to the emergency department of the HGM were registered and randomly selected for a more detailed profiling. Selected participants were approached by trained staff for informed consent; the first patient to be selected during each shift was selected randomly (from a list of the first five patients assisted); then, every fifth patient would be invited to participate. If a randomly selected patient was unable to respond to the nurses or the study survey team (i.e., unconscious, confused due to mental illness, severely ill, or under the influence of illicit drugs) informed written consent, demographics and risk factors data (including arterial hypertension), were obtained from a family member or spouse (legal guardians) by a medically qualified researcher. Even if the patient was not included in the study, he/she would be registered through the usual health information system, and therefore included in the full count of patient activity during the 30day snapshot period.

\section{Data collection}

For each patient presenting at the ED pre-designated data collection was performed by trained personnel, with skills for health surveillance and/or medical and nursing qualifications, using electronic capture. Direct observation was done using several trained health workers in each station and registered in paper-based case report forms (CRF) for full registry of the patient's profile (name, residential suburb, contact details and hospital identification, demographics, risk factor's data, medical history, clinical data, management information, immediate outcomes and time of discharge); researchers from INS entered data in electronic CRF on dedicated study laptops with restricted access ensuring the anonymity of each patient. Those patients admitted to wards or transferred to an elective unit were followed-up through their hospital records for the later completion of management and outcome data. At the completion of data collection, each case was allocated a final ICD 10 diagnosis (a weblink providing access to all ICD-10 coding for reference is provided). Participants were given a unique identifier to protect their anonymity and only de-identified data were used to generate study findings. Elevated BP was defined by systolic $\geq 140 \mathrm{mmHg}$ and/or diastolic BP $\geq 90$ mmHg (Grade I) - for adolescents above 15 years and adults ( $\geq 20$ years); grade II hypertension $160-179$ and/or $100-109$ and grade III $\geq 180$ and/or $\geq 110$ [13]. 
To describe the management of hypertension we used direct observation of patient's flow during the study, including collection of data on the infrastructure and human resources. Using the Package of Essential NCD interventions for primary health care in low-resource settings (PEN) [14] we selected diagnostic tools and medicines that are needed for hypertension management; we then consulted the reports from pharmacy and laboratory stocks to assess availability of diagnostics and medicines. The $\mathrm{WHO}$ essential medicines target of $80 \%$ was used to define availability. To define affordability the patient monthly capacity to purchase a medicine, we considered the national minimum wage and the WHO/HAI external reference pricing (available at the WHO/HAI database of medicine prices, availability, affordability and price components) [15] to calculate the number of work days, as well as the percentage of the monthly minimum wage that a patient needs to obtain the medicines prescribed.

\section{Data analysis}

Data was analysed using descriptive statistics (percentages and proportions); patient's flow in the health facility and availability/affordability are presented graphically.

\section{Ethical issues}

We have followed the STROBE guidelines for the conduct and reporting of observational studies [16]. The study had ethical approval by the National Bioethics Committee in Mozambique (IRB 0002657). Informed consent was obtained from all patients participating in the MOZART study.

\section{Results}

\section{Hypertension patients profile}

Out of the 8890 patients assisted during the study period we selected 1911 cases, of which 14 refused to participate and 55 were lost to follow up. For 197 patients data was incomplete. Among the remaining 1645 patients, 556 were children under 10 who were excluded from analysis. Of the remaining 1089 patients, 28 patients did not have their blood pressure measured and thus were excluded from analysis and 47 had the diagnosis of hypertension but the attending health worker had not registered the blood pressure values. Thus, 1014 patients were included in the analysis - 574 (56.6\%) females, 263 (16\%) adolescents (10-19 years) - of which 322 had high blood pressure; among these, $26(2.6 \%)$ were adolescents $>15$ years. Of the 322 hypertensive patients (females 168,52.2\%), 68 presented with systolic blood pressure $\geq 160 \mathrm{mmHg}$ and/or diastolic blood pressure $\geq 100 \mathrm{mmHg}$. From these hypertensive patients 37 were transferred to the hospital's intensive care unit, 6 (2\%) were admitted to hospital wards, and $3(1 \%)$ needed transfer for specialized care in referral hospitals due to acute complications.

\section{Patient flow}

Hypertensive patients had several stops during their journey inside the health facility. After initial triage at entry they could be sent directly to the ICU in case of hypertensive emergency/crisis. All other cases would wait for doctor's evaluation, blood collection for biological profiling at the laboratory, eventually performing chest X-ray and, finally, returning the results to the assisting doctor, who would decide if they were sent to the ICU, transferred to a specialized hospital, admitted to the wards or discharged. (Fig. 1).

\section{Facility resources}

Basic clinical equipment for diagnosis was available (sphygmomanometers, scales/altimeters, oxymeters, electrocardiograph, X-ray machine and ultrasound). However, no rapid tests were available (urine, blood glucose or HbA1c) for prompt risk stratification, and occasional stock-outs were registered for cholesterol and uric acid. Regarding human resources availability, the hospital had 38 general practitioners working around the clock at the ED who assisted patients and took decisions on: admitting them to the intensive care unit or transfer them to a referral hospital; admitting them into the hospital wards; sending them to book appointments for outpatient clinic for follow up with specialists within the hospital; or send them to a satellite health centers and the ED. There was no variation in availability of clinicians and other personal during the $24 \mathrm{~h}$. The staff of the whole hospital is presented in Fig. 2. No guidelines for risk stratification of hypertension were available in the consultation rooms, nor were manuals or algorithms.

\section{Availability \& Affordability of medicines}

The availability of medicines was $28 \%$ on average; 3 to $6 \%$ for calcium channel blockers (amlodipine) and aldosterone antagonist (spironolactone), respectively; between 51 to 70\% for adrenergic modifier/alpha-2 agonist (methyldopa), loop diuretic (furosemide) and angiotensin converting enzyme inhibitor (enalapril); only nifedipine $30 \mathrm{mg}$ was available in reaching the WHO essential medicines availability target of $80 \%$ (availability 145\%). Beta-blockers, angiotensin-II receptors antagonists, angiotensin converting enzyme inhibitor (lisinopril) and the combination (Hydrochlorothiazide and Amiloride) had 0\% availability during the study period (Table 1). For medicines not available at the health facility pharmacy patients would spend from 0 , $5-11.2 \%$ of their monthly wage to purchase a single medicine, corresponding to $0,2-3,4$ work days. The most affordable medicines found in this context were Hydrochlorothiazide, Methyldopa, Atenolol and Furosemide. The later - used to treat hypertension complications was the most affordable medicine, while Nifedipine 


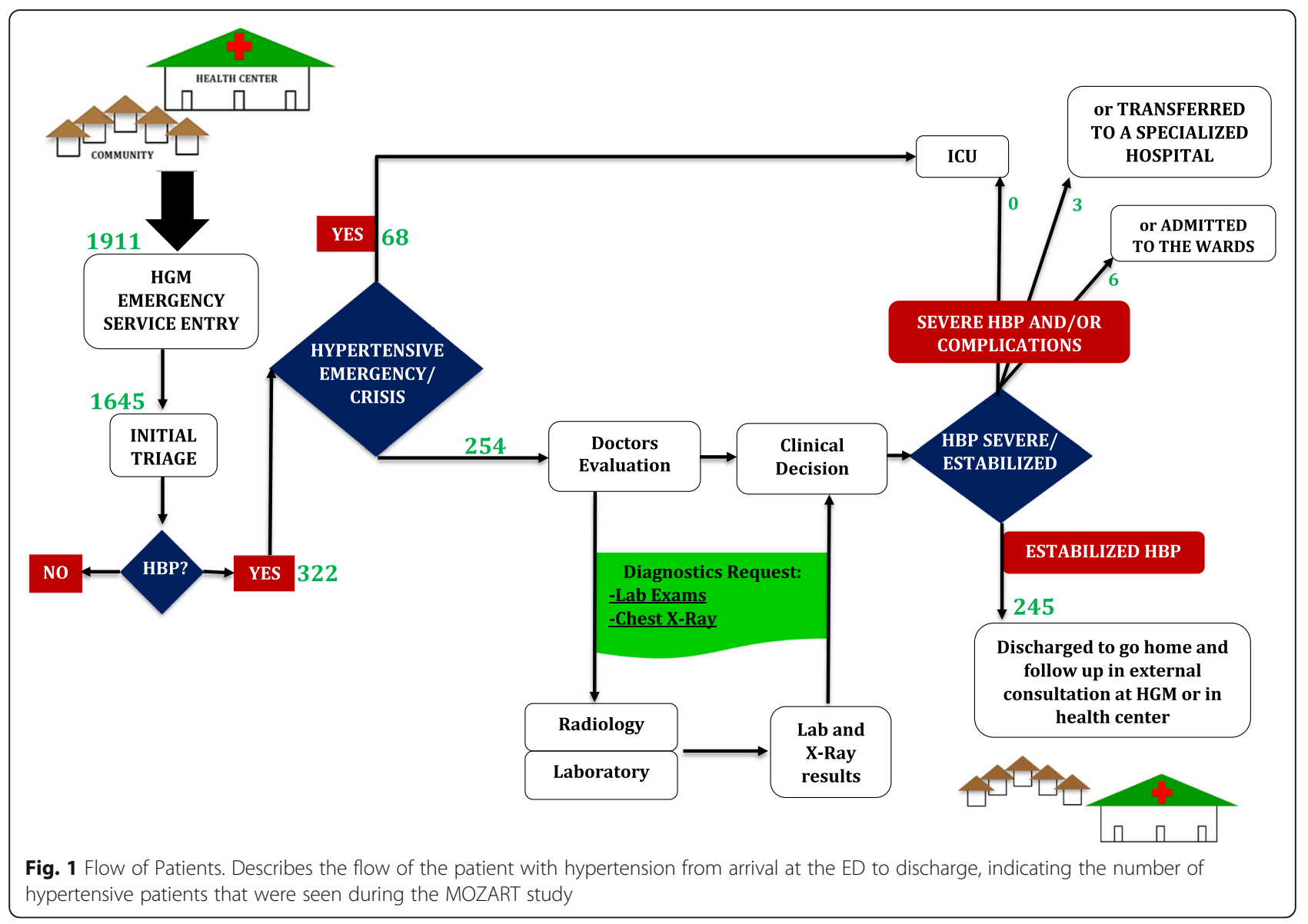

corresponded to $11.2 \%$ of the monthly minimum wage, approximately 3.4 work days. (Fig. 3 ).

\section{Discussion}

This study unveils a high occurrence of severe hypertension in patients assisted at the emergency department of this first urban hospital, in a context of health facility barriers to good quality of care for hypertensive patients, particularly i) the lack of availability of guidelines and clinical protocols for management for use by health professionals; ii) the absence of standardized risk stratification, follow up and referral; iii) deficient strategies to ensure continuum of care; and iv) low availability of key consumables for laboratorial diagnosis and medicines. These organizational weaknesses increase the risk of poor outcomes, particularly in patients already with complications, or in those who have grade severe hypertension and/or associated risk factors.

Recently, a clinical study from the same health facility reported on poor short-term outcomes of severe and complicated hypertension [17]. In this report, young adults with high-risk profile and multimorbidity had high case-fatality, occurrence of established and/or de novo target organ damage, and hospitalisation rates on six-month follow-up. Additionally, this hospital cohort had low control rates and a concerning pattern of multimorbidity (more than two coexisting chronic conditions) that significantly increase the pressure on already stretched health systems.

Mozambique's low rates of medical doctors and trained specialists [18, 19] - as well as nurses and allied professionals - are among the lowest in the world. To address the lack of workforce to tackle endemic infectious diseases (such as malaria, tuberculosis, HIV/AIDS and neglected parasitic diseases) the NHS has accommodated health professionals with basic- and mid-level training who are trained for triage and management of simple cases, using algorithms for diagnosis, management and referral [20] Most of these clinical guidelines are recommended or endorsed by the WHO, and are easily incorporated in the health systems due to being largely subsidized by international funding organizations. In contrast, for NCD clinical protocols and management algorithms are still not consensual, and rarely used in our setting, despite their known role in improving the quality of care. While recognizing that the number of health professionals is reduced, lack of risk-based management, unavailability of standard evidence-based clinical protocols and low access to essential anti-hypertensive drugs [21] - all essential to ensure high quality of care and prevent complications - are major 


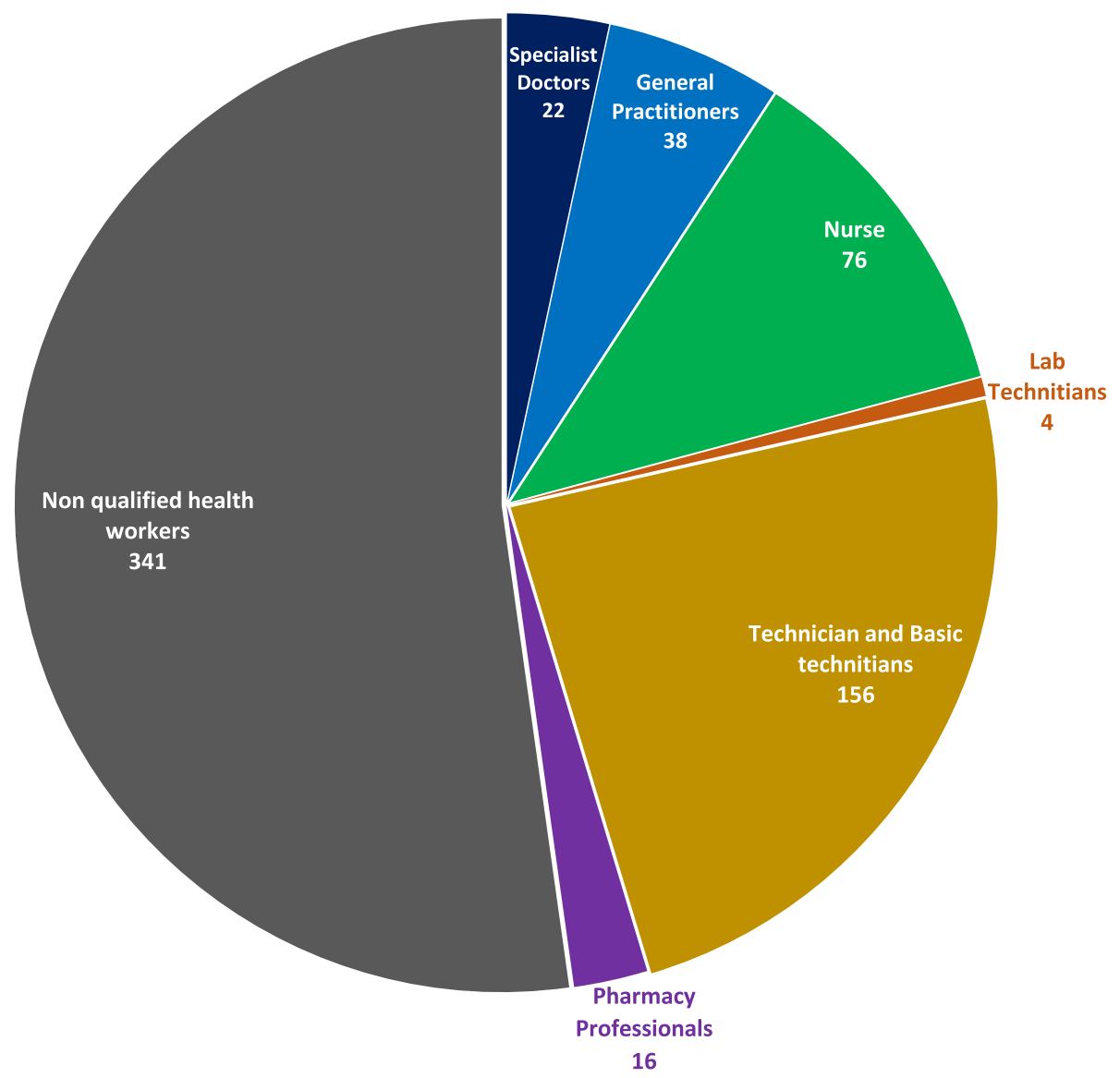

Fig. 2 Human Resources Availability. The distribution of health professionals involved in patient care and administrative roles in this health facility is presented, including personnel allocated to NCD complementary services. The numbers are shown per type of services needed

gaps in hypertension care. Addressing these gaps would allow standardization of care provided by front-line health workers and probably improve outcomes in secondary level health facilities. Indeed, the fact that hypertensionrelated complications have become more diagnosed at secondary and tertiary care levels in some settings in Africa, is probably indicative of poor management of hypertensive patients at primary health care level.

Because ED in low-income settings are often the first contact point of patients with the health system, strategies to reduce lost opportunities for early diagnosis, prompt management and secondary prevention are needed. ED may be the only or most used form of contact with the health system for certain population groups in our health system, particularly adolescents and men who are not covered by the strong maternal and child health care programs. Owing to the high prevalence of hypertension in Mozambique [4], point-of-care diagnostics tools - for instance rapid testing for biomarkers, portable electrocardiography and bedside ultrasound -should be used to facilitate risk stratification, detection of co-morbidities and identification of complications such has heart failure and kidney disease. In addition, clinical protocols must be made available to allow immediate treatment of those at high risk of target organ damage. Moreover, despite recognizing that ED are not the ideal setting for patient health education, counseling on healthy lifestyle, risk-free behavior and adherence to therapy to selected populations should probably be considered in such setting, to avoid loss of opportunities to prevent complications, to reduce hypertension-related morbidity and mortality, as well as to support continuity of treatment after diagnosis. The use of preventive medicine health workers - who are currently involved in maternal and child health disease prevention would probably be an important step towards better control of hypertension, if these professionals are trained to provide counseling and non-pharmacological therapy inside the health facility.

Inadequate supply of medicines is a major determinant for inadequate anti-hypertensive treatment and catastrophic spending in poor households and may (at least partially) explain the low levels of control in Mozambique $[4,6,22]$. Access to public hospitals is virtually free; patients pay $\$ 0.02$ at entry points for all procedures within 
Table 1 Hypertension Medicines Availability. Drugs and formulations prescribed to patients with hypertension, its estimated need and availability in the hospital

\begin{tabular}{|c|c|c|c|c|c|c|c|}
\hline Therapeutic Group & $\begin{array}{l}\text { Generic Name / International } \\
\text { Nonproprietary Name }\end{array}$ & $\begin{array}{l}\text { Pharmaceutical } \\
\text { form }\end{array}$ & Strength & Posology & $\begin{array}{l}\text { Estimated need } \\
\text { for one month }\end{array}$ & $\begin{array}{l}\% \text { of medicines } \\
\text { available }\end{array}$ & $\begin{array}{l}\text { SDG EM Targe } \\
\text { Availability }\end{array}$ \\
\hline $\begin{array}{l}\text { Thiazide diuretic }+ \\
\text { potassium sparing diuretic }\end{array}$ & $\begin{array}{l}\text { Hydrochlorothiazide } \\
\text { Amiloride }\end{array}$ & Tablets & $\begin{array}{l}50 \\
\mathrm{mg}+ \\
\mathrm{mg}\end{array}$ & 0,5 & 7905 & $0 \%$ & $<80 \%$ \\
\hline $\begin{array}{l}\text { Angiotensin Converting } \\
\text { Enzyme Inhibitor }\end{array}$ & Lisinopril & Tablets & $20 \mathrm{mg}$ & 1 & 15,810 & $0 \%$ & $<80 \%$ \\
\hline Calcium Channel Antagonists & Nifedipine & Tablets & $30 \mathrm{mg}$ & 1 & 15,810 & $145 \%$ & $>80 \%$ \\
\hline Calcium Channel Antagonists & Nifedipine & Tablets & $60 \mathrm{mg}$ & 1 & 15,810 & $0 \%$ & $<80 \%$ \\
\hline Beta blocker & Bisoprolol & Tablets & $5 \mathrm{mg}$ & 1 & 15,810 & $0 \%$ & $<80 \%$ \\
\hline Beta blocker & Atenolol & Tablets & $50 \mathrm{mg}$ & 0,5 & 7905 & $0 \%$ & $<80 \%$ \\
\hline $\begin{array}{l}\text { Angiotensin-II Receptor } \\
\text { Antagonist }\end{array}$ & Irbesartan & Tablets & $300 \mathrm{mg}$ & 1 & 15,810 & $0 \%$ & $<80 \%$ \\
\hline $\begin{array}{l}\text { Angiotensin Converting } \\
\text { Enzyme Inhibitor }\end{array}$ & Enalapril & Tablets & $20 \mathrm{mg}$ & 1 & 15,810 & $60 \%$ & $<80 \%$ \\
\hline $\begin{array}{l}\text { Adrenergic modifier } \\
\text { / alpha } 2 \text { agonist }\end{array}$ & Methyldopa & Tablets & $250 \mathrm{mg}$ & 1 & 15,810 & $51 \%$ & $<80 \%$ \\
\hline Aldosterone antagonist & Spironolactone & Tablets & $25 \mathrm{mg}$ & 1 & 15,810 & $6 \%$ & $<80 \%$ \\
\hline Loop diuretic & Furosemide & Tablets & $40 \mathrm{mg}$ & 1 & 15,810 & $70 \%$ & $<80 \%$ \\
\hline
\end{tabular}

Obs: The availability was calculated for all patients (527) reported to have hypertension assisted in October 2017 (considering that this number includes the patients transferred from the ED, and medication should be available for all of them). SDG EM: Sustainable Development Goals Essential Medicines

the health facility and $\$ 0.08$ per full prescription, the total amount charged corresponding to $0.1 \%$ of the country's minimum wage [11]. However, out-of-pocket expenditure for continuum of care in hypertension may be prohibitively expensive for the poorest households, as communities have high levels of poverty and informal employment, and almost no access to affordable private health insurance mechanisms. In Bangladesh, NCD-afflicted families allocate a greater share of household expenditures for medical care than households without NCDs and have almost seven times higher probability of incurring catastrophic medical expenditure, as well of selling assets or borrowing from informal sources to finance treatment cost [23]. In Mozambique, a considerable proportion of the household budget for families living on the national minimum wage is used to buy any anti-hypertensive, mainly if the patient needs more than one hypertensive medicine. Medical therapy entails large out-of-pocket expenditures and increases the likelihood of household impoverishment as shown in Kyrgyzstan, where households

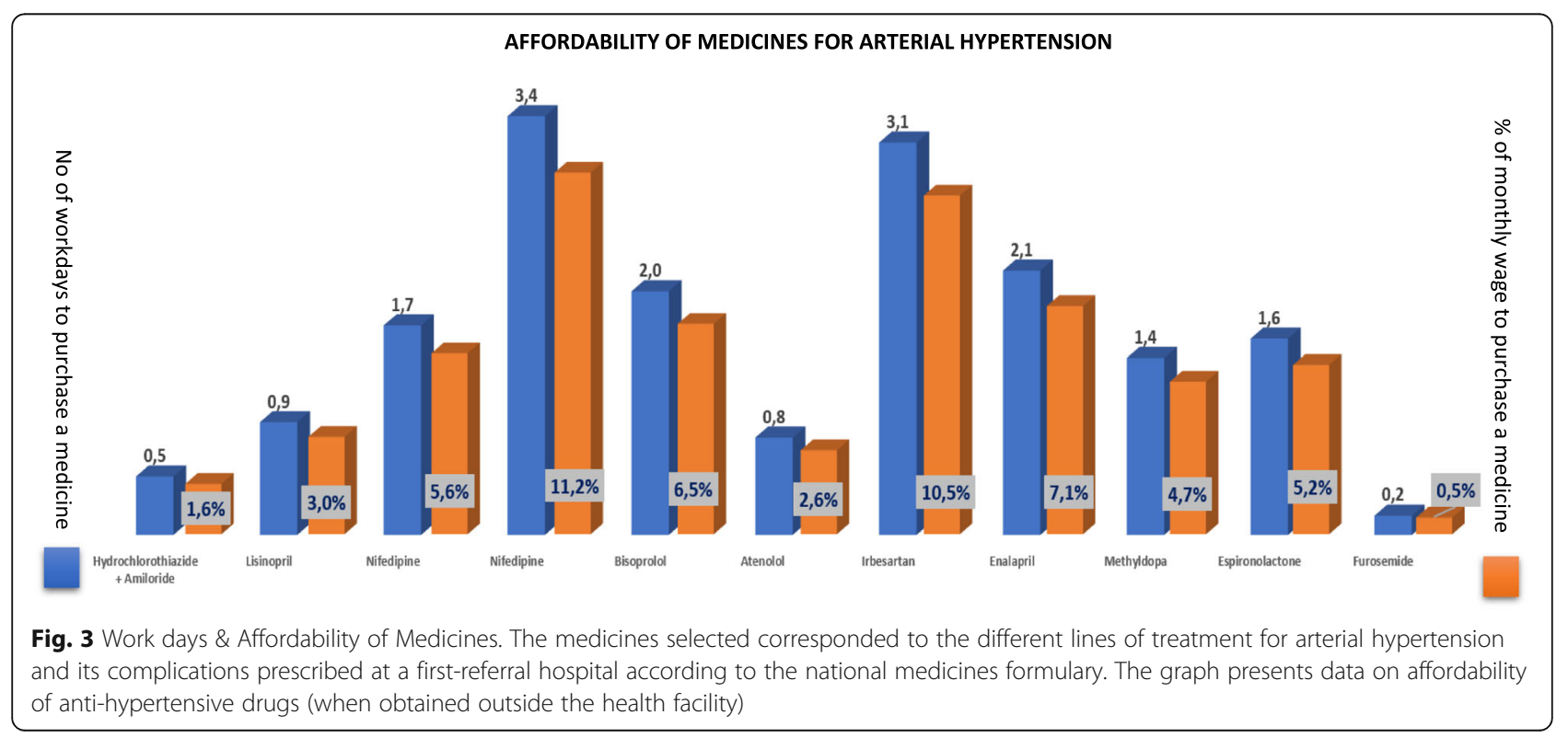


with an hypertensive patients had significantly higher total expenditure on health and drug therapy, thus being more prone to catastrophic health spending [22]. Similarly, it has been shown that patient costs associated with obtaining care for hypertension in public health care facilities in Kenya include substantial direct and indirect costs, as well as high rates of catastrophic costs [24]. Therefore, systems to assess the unmet needs of anti-hypertensive drugs, improve the whole supply chain in the public sector and financial risk protection for patients from these poor communities are needed.

Health System related factors impact on the capacity to control blood pressure [25-27] In African countries Health Systems are primarily oriented to managing infectious diseases, and therefore health professionals are unprepared to deal with NCD, given the scarcity of resources in health facilities [28]. The strategy of taskshifting - defined as the rational distribution of health care duties from physicians to non-physicians health care providers - is one of the effective approaches that has been used to address lack of human resources in Africa [29], including for management of $\mathrm{HBP}$ [30, 31]. Considering the experience of Mozambique's NHS in task shifting in obstetrics, surgery and mental health [20, 32], we strongly believe that targeted context-specific changes to the Health System in Mozambique can also be done to allow task-shifting for the diagnosis and management of hypertensive patients to occur, in order to improve rates of control and outcomes.

Limitations: Despite the acknowledging that the "snapshot" taken during one month cannot be fully representative of the situation, we believe that this description of hypertension care in ED constitutes an initial step towards addressing poor outcomes and understanding the organizational changes needed to improve care in our setting. Moreover, this model can be ameliorated and replicated for assessment of health care for other risk factors and NCD, thus supporting priority setting and selection of the most efficient interventions and health services changes that can be done to create contexttailored NCD clinics in Africa.

\section{Conclusions}

Critical gaps in health facility readiness to address arterial hypertension seen in ED were uncovered in this highly prevalent low-income urban setting, including lack of clinical protocols, insufficient availability of diagnostics and essential medicines, as well as low affordability of the families to guarantee continuum of care. Our results show opportunities for improvement at the provider's level, particularly of the organizational and managerial processes. Innovative financing mechanisms for the health system are needed to support the poorest, improve the rates of hypertension control and prevent poor outcomes.

\section{Abbreviations}

AIDS: Acquired Immunodeficiency Syndrome; ED: Emergency Department; HAl: Health Alliance International; HbA1c: Glycated hemoglobin; HBP: High Blood Pressure; HGM: Mavalane General Hospital (Hospital Geral de Mavalane); HIV: Human Immunodeficiency Virus; INS: National Health Institute (Instituto Nacional de Saúde); NCD: Non-Communicable Diseases; NHS: National Health Service; WHO: World Health Organization

\section{Acknowledgments}

We sincerely thank all the staff at Hospital Geral de Mavalane and members of Instituto Nacional de Saúde, Mozambique, who participated in data collection for the MOZART study. Finally, our gratitude to Professor Virgílio do Rosário for his comments to the initial draft of the manuscript.

\section{Authors' contributions}

All authors had full access to all the data in the study and take responsibility for the integrity of the data and the accuracy of the data analysis. AOM and SS had the original idea for and designed the study. NB and EJ made contributions to the study design and participated in data extraction from the database. NB, EJ, CM, JJ and MA participated in the data collection for diagnostics and treatment. NB and EJ wrote the initial report. NB, EJ, CM, JJ, MC, SS and AOM participated in data interpretation and analysis. AOM and NB prepared the final manuscript. All authors contributed to subsequent revisions and have read and approved the manuscript.

\section{Funding}

The MOZART Study was co-funded by the Instituto Nacional de Saúde of Mozambique, the National Health and Medical Research Council of Australia (1044897) and a Pfizer Investigator Initiated Research Grant (WT221693). AM and SS received the awards. The funders had no role in the study design, data collection and analysis, decision to publish, or preparation of the manuscript.

\section{Availability of data and materials}

The datasets used and/or analyzed during the current study are available from the corresponding author on reasonable request.

Ethics approval and consent to participate

This study was approved by Mozambique's National Bioethics Committee (IRB 00002657). Participants gave written informed consent before enrollment.

\section{Consent for publication}

Not applicable.

\section{Competing interests}

Not applicable.

\section{Author details}

${ }^{1}$ Mozambique Institute for Health Education and Research, Cidade de Maputo, Mozambique. ${ }^{2}$ Instituto Nacional de Saúde, Vila de Marracuene, Estrada Nacional Nº1, Parcela N³943, Província de Maputo, Mozambique. ${ }^{3}$ Hospital Geral de Mavalane, Cidade de Maputo, Mozambique. ${ }^{4} T o r r e n s$ University, Adelaide, Australia. ${ }^{5}$ Universidade Eduardo Mondlane, Cidade de Maputo, Mozambique.

Received: 5 July 2019 Accepted: 9 December 2019

Published online: 18 December 2019

\section{References}

1. Damasceno A, Azevedo A, Silva-Matos C, Prista A, Diogo D, Lunet N. Hypertension prevalence, awareness, treatment, and control in Mozambique: urban/rural gap during epidemiological transition. Hypertension. 2009;54(1):77-83.

2. Mills KT, Bundy JD, Kelly TN, Reed JE, Kearney PM, Reynolds K, et al. Global disparities of hypertension prevalence and control: a systematic analysis of population-based studies from 90 countries. Circulation. 2016;134(6):441-50.

3. Gómez-Olivé FX, Ali SA, Made F, Kyobutungi C, Nonterah E, Micklesfield L, et al. Regional and sex differences in the prevalence and awareness of hypertension. Glob Heart. 2017;12(2):81-90. 
4. Jessen N, Damasceno A, Silva-Matos C, Tuzine E, Madede T, Mahoque R, et al. Hypertension in Mozambique: trends between 2005 and 2015. J Hypertens. 2018;36(4):779-84.

5. Damasceno A, Mayosi BM, Sani M, Ogah OS, Mondo C, Ojji D, et al. The causes, treatment, and outcome of acute heart failure in 1006 Africans from 9 countries. Arch Intern Med. 2012;172(18):1386-94.

6. Damasceno A, Gomes J, Azevedo A, Carrilho C, Lobo V, Lopes H, et al. An epidemiological study of stroke hospitalizations in Maputo, Mozambique: a high burden of disease in a resource-poor country. Stroke. 2010;41(11):2463-9.

7. da Saúde M. Plano estratégico nacional de prevenção e controlo das doenças não transmissíveis para o período; 2008-2014.

8. WHO. Global strategy for the prevention and control of noncommunicable diseases, World Health Organization 2000.

9. Ministério da Saúde, CMAM. Gestão, controlo e dispensa de medicamentos: Manual de Procedimentos dos Centros de Saúde. USAID projecto deliver. 2008, 3a Edição.

10. Ministério da Saúde, DNF. Lista Nacional de Medicamentos Essenciais. Projecto SIAPS, 2017

11. Boletim da República N 96, I série, 16 de Maio de 2018, Diplomas Ministeriais n. ${ }^{\circ}$ 40/2018 a n. ${ }^{\circ}$ 47/2018, de 16 de Maio.

12. Mocumbi AO, Cebola B, Muloliwa A, Sebastião F, Sitefane SJ, Manafe N, et al. Differential patterns of disease and injury in Mozambique: new perspectives from a pragmatic, multicenter, surveillance study of 7809 emergency presentations. PLoS One. 2019;14(7):e0219273. https://doi.org/10. 1371/journal.pone.0219273

13. Mancia, et al. 2013 ESH/ESC guidelines for the management of arterial hypertension: the task force for the management of arterial hypertension of the European Society of Hypertension (ESH) and of the European Society of Cardiology (ESC). J Hypertens. 2013;31(7):1281-357.

14. WHO. Package of Essential Noncommunicable (PEN) Disease Interventions for Primary Health Care in Low-Resource Settings, World Health Organization 2013, ISBN: 9789241506557.

15. WHO/HAl Database of medicine prices, availability, affordability and price components. Available from: https://haiweb.org/what-we-do/priceavailability-affordability/price-availability-data/

16. Cuschieri S. The STROBE guidelines. Saudi J Anaesth. 2019;13:S31-4. https:// doi.org/10.4103/sja.SJA_543_18.

17. Manafe N, Matimbe RN, Daniel J, Lecour S, Sliwa K, Mocumbi AO. Hypertension in a resourced limited setting: poor outcomes on short-term follow up in an Urban Hospital in Maputo, Mozambique. J Clin Hypertens (Greenwich). 2019 Nov 25. https://doi.org/10.1111/jch.13732.

18. Mocumbi AO, Carrilho C, Aronoff-Spencer E, Funzamo C, Patel S, Preziosi M, et al. Innovative strategies for transforming internal medicine residency training in resource-limited settings: the Mozambique experience. Acad Med. 2014;89(8 Suppl):S78-82.

19. Noormahomed EV, Mocumbi AO, Ismail M, Carrilho C, Patel S, Nguenha A, et al. The medical education partnership initiative effect on increasing health professions education and research capacity in Mozambique. Ann Glob Health. 2018;84(1):47.

20. Bergström S, McPake B, Pereira C, Dovlo D. Workforce innovations to expand the capacity for surgical services. In: Debas HT, Donkor P, Gawande A, Jamison DT, Kruk ME, Mock CN, editors. Essential surgery: disease control priorities, third edition (V1). Washington (DC): The International Bank for Reconstruction and Development / The World Bank; 2015.

21. World Health Organization HEARTS Technical package for cardiovascular disease management in primary health care: evidence-based treatment protocols. Geneva: World Health Organization; 2018 (WHO/NMH/NVI/18.2). Licence: CC BY-NC-SA 3.0 IGO. ISBN 9789241511377.

22. Murphy A, Jakab M, McKee M, Richardson E. Persistent low adherence to hypertension treatment in Kyrgyzstan: how can we understand the role of drug affordability? Health Policy Plan. 2016;31(10):1384-90.

23. Datta BK, Husain MJ, Husain MM, Kostova D. Noncommunicable diseaseattributable medical expenditures, household financial stress and impoverishment in Bangladesh. SSM Popul Health. 2018;6:252-8.

24. Oyando R, Njoroge M, Nguhiu P, Kirui F, Mbui J, Sigilai A, et al. Patient costs of hypertension care in public health care facilities in Kenya. Int J Health Plann Manag. 2019:e1166-78. https://doi.org/10.1002/hpm.2752.

25. Doroodchi H, Abdolrasulnia M, Foster JA, Foster E, Turakhia MP, Skelding KA, et al. Knowledge and attitudes of primary care physicians in the management of patients at risk for cardiovascular events. BMC Fam Pract. 2008;9:42.
26. Lulebo AM, Mapatano MA, Kayembe PK, Mafuta EM, Mutombo PB, Coppieters Y. Assessment of hypertension management in primary health care settings in Kinshasa. Democratic Republic of Congo BMC Health Serv Res. 2015;15:573.

27. Pellegrini F, Belfiglio M, De Bernadis G, Franciosi M, Di Nardo B, Grienfield S, et al. Role of organizational factors in poor blood pressure control in patients with type 2 diabetes. Arch Intern Med. 2003;163:473-80.

28. Alleyne G, Hancock C, Hughes P. Chronic and non-communicable diseases: a critical challenge for nurses globally. Int Nurs Rev. 2011;58:328-31.

29. Ogedegbe G, Gyamfi J, Plange-Rhule J, Surkis A, Rosenthal MD, Airhihenbuwa C, et al. Task shifting interventions for cardiovascular risk reduction in low-income and middle-income countries: a systematic review of randomized controlled trials. BMJ Open. 2014;4:e005983. https://doi.org/ 10.1196/bmjopen-2014-005983.

30. Mendis S, Johnston SC, Fan W, Oladapo O, Cameron A, Faramawi FM. Cardiovascular risk management and its impact on hypertension control in primary care in low -resource settings: a cluster randomized trial. Bull World Health Organ. 2010;88:412-9.

31. Adeyemo A, Tayo BO, Luke A, Ogedegbe O, Durazo-Arvizu R, Cooper RS. The Nigerian-antihypertensive adherence trial (NA-HAT): a communitybased randomized trial. J Hypertens. 2013;31(1):201-7.

32. Oquendo MA, Duarte C, Gouveia L, Mari JJ, Mello MF, Audet CM, et al. Building capacity for global mental health research: challenges to balancing clinical and research training. Lancet Psychiatry. 2018;5(8):612-3.

\section{Publisher's Note}

Springer Nature remains neutral with regard to jurisdictional claims in published maps and institutional affiliations.
Ready to submit your research? Choose BMC and benefit from:

- fast, convenient online submission

- thorough peer review by experienced researchers in your field

- rapid publication on acceptance

- support for research data, including large and complex data types

- gold Open Access which fosters wider collaboration and increased citations

- maximum visibility for your research: over $100 \mathrm{M}$ website views per year

At BMC, research is always in progress.

Learn more biomedcentral.com/submissions 